\title{
Real Estate Portfolio Construction and Estimation Risk
}

\section{A Paper presented at the 7th European Real Estate Society Conference, Bordeaux, France, 14-17 June 2000}

\author{
Stephen Lee \& Simon Stevenson $^{\dagger}$
}

\begin{abstract}
The use of MPT in the construction real estate portfolios has two serious limitations when used in an ex-ante framework: (1) the intertemporal instability of the portfolio weights and (2) the sharp deterioration in performance of the optimal portfolios outside the sample period used to estimate asset mean returns. Both problems can be traced to wide fluctuations in sample means Jorion (1985). Thus the use of a procedure that ignores the estimation risk due to the uncertain in mean returns is likely to produce sub-optimal results in subsequent periods. This suggests that the consideration of the issue of estimation risk is crucial in the use of MPT in developing a successful real estate portfolio strategy. Therefore, following Eun \& Resnick (1988), this study extends previous ex-ante based studies by evaluating optimal portfolio allocations in subsequent test periods by using methods that have been proposed to reduce the effect of measurement error on optimal portfolio allocations.
\end{abstract}

$\dagger$ Department of Land Management and Development, Faculty of Urban and Regional Studies,

The University of Reading, Reading RG6 6AW, England.

Phone: +44 118931 6338, Fax: +44 118931 8172, E-mail: S.L.Lee@ reading.ac.uk

$\ddagger$ Department of Banking \& Finance, Graduate School of Business, University College Dublin, Blackrock, Co Dublin, Ireland.

Phone: +353 1706 8825, Fax: +353 1283 5482, E-mail: simon.stevenson@ucd.ie

Key Words: Ex-post optimisation, ex-ante portfolio performance, Bayes-Stein estimation. 


\section{Real Estate Portfolio Construction and Estimation Risk}

\section{Introduction}

Investors in real estate have typically attempted to diversify portfolios through a process of naive diversification. Recently Modern Portfolio Theory (MPT) has been advocated as a more rational approach to the construction of real estate portfolios to identify the 'best' combination of assets to hold (Lee, 1992). In this approach, the importance of each asset is evaluated in terms of its individual relative risk and return characteristics, as measured by its mean and standard deviation, and its portfolio risk as characterised by its correlation with other assets. Given these parameters MPT will find that combination of assets that, for each level of risk, will offer the highest level of return. Such work typically uses historic ex-post data to test the effectiveness of such portfolio strategies. However, historic data by its nature is certain, consequently the portfolio holdings are the 'best' that could have been achieved in the past. This is equivalent to playing the portfolio investment game with a marked deck, Madura and Abernathy (1985). Fund managers, however, are hired to construct portfolios, which yield high ex-ante rather than ex-post risk-adjusted returns, and are therefore forced to play with an unmarked deck. However, when the application of MPT has been tested in ex-ante framework the ex-post results tend to perform poorly.

The classical approach to portfolio construction using MPT has two serious defects: (1) the intertemporal instability of the portfolio weights (Lee, 1997) and (2) the sharp deterioration in performance of the optimal portfolios outside the sample period used to estimate asset mean returns, Jorion (1985). In effect, due to the fact that the inputted parameters are unstable, the estimated optimal allocations can differ markedly between periods. This is made even more acute as optimiser typically produce portfolios with extreme holdings in a limited number of assets with some assets taking zero weights while others have very large allocations. Black and Litterman (1992) refer to these as corner solutions. Although the resulting portfolios are optimal in the statistical sense, the results would be unacceptable to any prudent portfolio manager (Jorion 1985). Such corner solutions portfolios quickly become sub-optimal with changes in the means over time, leading to a further reduction in ex-ante performance. In addition such extreme portfolio allocations assets seem to be against the spirit of diversification, Michaud (1989). One way to control for such extreme holdings is to place constraints (upper and lower bounds) on the amount any one asset, or group of assets, can have in the optimum portfolio (Byrne and Lee, 1995 and Stevenson 2000b). Indeed papers such as Frost and Savarino (1988) and Chopra (1993) suggest portfolio optimisations, which are subject to such constraints, have better ex-ante performance compared with unconstrained solutions. However, any constraints are likely to be arbitrary, leading to the results being hard to generalise. For example, one possible constrained portfolio is the equally weighted naï ve portfolio. Morrell (1993), however, argues that that it is generally not possible for property funds achieve equal-weighting in a portfolio and at the same time be represented in key market segments. In addition fund managers typically desire to maintain weights similar to a benchmark portfolio. Also at a practical level due to the indivisibility of property and the marked differences in lot size between say the Office and Industrial sectors an equal-weighted portfolio strategy would be impossible to implement. Thus an equal-weighted portfolio is therefore probably not a 
realistic, or even a desirable goal of fund managers. In addition such an approach fails to tackle the fundamental reason for the major shifts in portfolio allocations over time, the instability in the sample means. In contrast the estimation error in variances and covariances is not as much of concern since these parameters are relatively stable over time and therefore are more precisely estimated. Studies such as Kalberg \& Ziemba (1984), Chopra \& Ziemba (1993) and Stevenson (2000a) have found similar results. Thus the use of a portfolio selection procedure based on historical parameters that ignores the estimation risk due to the uncertain in mean returns is likely to produce sub-optimal results in subsequent periods. Indeed previous work on the application of MPT to the real estate portfolio shows this to be the case, Meyer and Webb (1991), Mueller and Laposa (1995) and Pagliari, Webb and Del Casino (1995).

The above discussion suggests that the consideration of the issue of estimation risk is crucial in the use of MPT in developing a successful real estate portfolio strategy. Therefore, following Eun and Resnick (1988) and Kwok (1990), this study extends previous ex-post based real estate based studies by evaluating optimal portfolio allocations in subsequent test periods by using a method that have been proposed to reduce the effect of measurement error on optimal portfolio allocations. Furthermore, the mean-variance model used here does not allow for lending, short sales or borrowing. Lending, borrowing and short sales opportunities are eliminated, as their use is inconsistent with institutional investor's portfolio management practices. In addition to which short selling significantly increase the adverse effect of estimation error on portfolio selection, Jorion (1992). Finally, no consideration of transaction costs and taxes has been included in this study.

\section{Previous Studies}

A number of studies have investigated the ex-ante performance of ex-post portfolio efficient allocations in both equity and real estate markets. The first study by Logue (1982) used historical data on foreign country stock market indices to test a number of international portfolio management strategies. In particular would a passive international portfolio strategy outperform the returns of a US index fund, or an actively managed international portfolio? To construct an ex-ante optimal set of portfolio weights for any given year, Logue used the monthly returns, variances, and covariance for stock markets for the prior five years. This approach was based on the assumption that historical data, which are themselves a combination of market returns and currency fluctuations, provide optimal forecasts for the behaviour of security returns over the coming year. The analysis showed that the mean/risk ratio for optimal ex post international portfolios exceeded, by a wide margin, the corresponding ratio for ex ante international optimal portfolios and for the US index. The author therefore concluded that using a simple Markowitz portfolio selection technique, with historical data as input, produces ex-ante optimal portfolios that are worse than those produced by ex-post optimal portfolios. Thus if portfolio managers had followed a passive buy-and-hold strategy they would be better off than if they engage in an active investment strategy.

Madura and Abernathy (1985) also examined the performance of global stock portfolios prescribed by ex-post models. Using weekly stock market index returns for eight countries 
for the period, January 1978 to January 1981 the authors segmented the data into five subperiods of equal length and for each period, a mean variance algorithm was used to generate ex-post efficient portfolios. The ex-post optimal portfolio weights then formed the basis for investment in the subsequent "ex-ante" period. Thus all information for the ex-ante strategy was developed from the previous period. Madura and Abernathy considered the performance of three mean-variance efficient portfolios. A low-risk portfolio which exhibited the least variance in an ex-post basis, a high risk-portfolio produce which showed the highest expected return, and an intermediate risk portfolio which displayed the highest ex-post return per unit risk Sharpe Ratio (Sharpe, 1966, 1994). For the ex-ante strategy to be described as effective, it was expected to outperform a naive portfolio of the international stocks and the US index. In constructing these ex-post optimal portfolios Madura and Abernathy observed that the returns and standard deviations in each country performed differently in the various sub-periods. In other words the data was not stationary. Consequently performance of the ex-post based efficient portfolios behaved poorly in subsequent periods. In particular on an ex-ante basis the analysis showed that neither the naive nor the mean-variance international portfolios produced consistently higher returns relative to the US index. While in terms of risk, the mean-variance low risk portfolio was the only strategy, which consistently exhibited a lower standard deviation than the US index. Also no single strategy could be distinguished as superior when the risk-adjusted performance of the various strategies was compared. The authors concluding that the difference between "potential gains from an ex-post analysis" and "realised gains from an ex-ante analysis" may be substantial.

Within the real estate market three studies have looked at the performance of MPT portfolio allocations in subsequent periods. The first by Meyer and Webb (1991) analysed a tenyear period from 1978 to 1988 using NCREIF returns for Office, Retail, R\&D/office, and Warehouses. Their portfolio optimisations found different mixes for different time periods. Warehouse and R\&D/office was the strongest in the 1978 to 1983 sub-period, while during the 1983 to 1988 period Warehouse and Retail had the best risk/return. They concluded that returns move differently during different time periods and thus a single portfolio allocation strategy may not be optimal during different sub-periods.

The second study by Mueller and Laposa (1995) investigated what allocation institutional investors should make to the different property-types: Retail, Office, Apartments and Warehousing using quarterly data in the US. In particular Mueller and Laposa argue that property-type returns have gone through cycles in the past and estimating future returns depends on the cyclic movement within each property-type. In order to identify which property-type to invest in the future investors need to be aware of how each property-type as performed in different phases of the cycle. The authors therefore divided the NCREIF returns data into different periods based on three cyclic indicators: total returns, capital appreciation and GDP growth. They then constructed efficient frontiers in each of the subperiods and found different allocations both in terms of assets chosen and portfolio weights during the different periods. Mueller and Laposa concluded that in developing their future allocations, investor's need to be aware of the current and future phases of the cycle in order to determine future portfolio compositions. 
Finally Pagliari, et al (1995) set out to test whether the strict application of MPT offered superior returns to naive or average-mix (market weight) strategies for institutional investors. Using 15 years quarterly returns divided the data three, five-year sub-periods, the authors showed that while MPT yields optimal ex-post portfolios, its use as an ex-ante portfolio allocation strategy could lead to mixed results. That is, MPT portfolios constructed from ex-post data and extrapolated into future periods, may or may not outperform naive and average-mix strategies. Consequently like Madura and Abernathy, the authors noted that while it is easy to determine the best portfolios ex-post determining the correct mix in the future is more difficult. In other words the studies show that the effective application of an ex-ante MPT based portfolio strategy depends heavily on the accuracy of the portfolio inputs.

Consequently the successful application of MPT to the real estate portfolio construction process requires an optimisation procedure that explicitly takes account of estimation risk. The following section therefore uses one such approach ${ }^{1}$, the Bayes-Stein shrinkage estimator in deriving the ex-post weights of the portfolio with the highest return per unit risk, on the efficient frontier, and tests its performance to see if the reduction in estimation leads to greater ex-ante performance in subsequent periods.

\section{Methodology}

In order to test the effectiveness of ex-post optimisation in subsequent periods efficient portfolios were formed in a number of sub-period and the portfolio weights held into the next period, as in the approach of Pagliari, et al (1995). However, unlike Pagliari, et al, who analysed the whole efficient frontier in each period, only four ex-post portfolios are examined here, following the approaches of Eun and Resnick (1988) and Madura and Abernathy (1985).

The four strategies used are those suggested and thoroughly described by Eun and Resnick (1988). The first strategy is the equal-weighted naï ve portfolio. Eun and Resnick view this approach as a naive diversification strategy in the attempt to capture some of the potential gains from sector/regional diversification. The naï ve portfolio, as discussed above, also represents one of the many possible constrained portfolios and so should perform well in an ex-ante framework as it 'constrains' the impact of instability in the input parameters, Frost and Savarino (1988) and Chopra (1993). However, as also highlighted previously such a portfolio is both undesirable and generally impossible to hold. Nonetheless the naï ve portfolio provides a convenient benchmark of ex-ante performance against which to test the other strategies.

The second strategy uses the weights of the Minimum-Variance Portfolio (MVP) as the optimal ex-ante weights. Jorion's (1985) simulation analysis suggests that the MVP is less prone to measurement error than the classical tangency portfolio because the optimal solution of the MVP depends only on the sample covariance matrix (and not the mean-

\footnotetext{
${ }^{1}$ A number of methods have been suggested to handle estimation risk within a portfolio context, see Michaud (1998) for a review.
} 
return vector), which is relatively stable over time. Indeed the results of Pagliari, et al (1995) and Madura and Abernathy, (1985) suggest that such a portfolio is qualitatively more stable, in its risk characteristics, than other portfolios on the efficient frontier and so is more likely to perform well in subsequent periods. This view has been supported in empirical studies such as Jobson \& Korkie (1981) and Stevenson (1999). Stevenson (1999) analysed a total of 38 international equity markets including 15 emerging markets. Due to the non-normality present in emerging market returns, two alternative downside risk measures were also utilised in addition to the conventional variance. The results show that all three minimum risk portfolios out-performed the alternative tangency portfolios on an outof-sample basis.

The third method, called the Certainty-Equivalence Tangency (CET) Portfolio strategy by Eun and Resnick or the Classical Sharpe portfolio here, computes the weights of the expost tangency portfolio and uses them as the ex-ante portfolio weights, identified by the following maximisation problem:

$$
\operatorname{Max} \theta=\frac{\bar{r}_{p}-r_{f}}{\sigma_{p}^{2}}
$$

Where $\bar{r}_{p}$ is the expected return on portfolio $p, r_{f}$ is the risk-free rate of return and $\sigma_{p}^{2}$ is the variance of the portfolio. The weights in this portfolio are then the ones offering the highest ex-post mean return per unit risk. Furthermore the composition of such a tangency portfolio is independent of the investors' preference structure, Tobin (1958). Note also that $\theta$ in the above formulation is, in fact, the ex-post Sharpe Ratio (Sharpe, 1966, 1994) performance measure. Consequently it is the portfolio that is most desirable to all investors. In conducting the analysis the risk-free rate of return was assumed to be zero for simplicity.

The final portfolio strategy considered is the Bayes-Stein shrinkage estimator to calculate the expected returns vector. The use of Bayes-Stein estimators is designed to reduce the degree of estimation error and furthermore, decrease the tendency for asset allocation studies to arrive at corner solutions. A further advantage to the use of such estimators is that empirical evidence, such as Jorion (1985), Chopra, Hensel \& Turner (1993) and Stevenson (1999, 2000a) have provided evidence that the ex-ante performance of optimal portfolios improves substantially. The premise behind the Bayes-Stein approach is that due to the sensitivity of the estimated allocations to variations in the parameters, and to relatively extreme inputs, the means of the assets are 'shrunk' towards a global mean. This effectively reduces the difference between extreme observations, thus aiding in the attempt to reduce estimation error. The general form for the estimators can be defined as follows:

$$
\mathrm{E}\left(\mathrm{r}_{\mathrm{i}}\right)=\mathrm{w} \overline{\mathrm{r}}_{\mathrm{g}}+(1-\mathrm{w}) \overline{\mathrm{r}}_{\mathrm{i}}
$$

Where $\mathrm{E}\left(\mathrm{r}_{\mathrm{i}}\right)$ is the adjusted mean, $\overline{\mathrm{r}}_{\mathrm{i}}$ is the original asset mean, $\overline{\mathrm{r}}_{\mathrm{g}}$ the global mean and $\mathrm{w}$ the shrinkage factor. Jorion $(1985,1986)$ shows that the shrinkage factor can be estimated from a suitable prior as follows: 


$$
\begin{aligned}
& \hat{\mathrm{w}}=\frac{\hat{\lambda}}{(\mathrm{T}+\hat{\lambda})} \\
& \hat{\lambda}=\frac{(\mathrm{N}+2)(\mathrm{T}-1)}{\left(\mathrm{r}-\mathrm{r}_{0} 1\right)^{\prime} \mathrm{S}^{-1}\left(\overline{\mathrm{r}}-\mathrm{r}_{\mathrm{g}} 1\right)(\mathrm{T}-\mathrm{N}-2)}
\end{aligned}
$$

Where $T$ is the sample size and $S$ is the sample covariance matrix. Three slightly different techniques are used to shrink the data. The first simply assumes that the within group means for the office, retail and industrial sectors are equal to the overall IPD national mean. The second and third methods use the Jorion prior using alternative definitions of the global mean. The second uses the overall IPD Index, with all nine series shrunk towards this figure. The third uses each of the sector indices as the global mean. Therefore, the regional markets in each respective sector are shrunk in relation to the national sector index. This is consistent with the argument made by Jorion (1985) that the use of a single global mean is hard to reconcile with the idea that a risk-return trade-off exists. Therefore, if it were assumed that there exists a risk-return trade-off between the office, retail and industrial sectors, it would be appropriate to use each sectors mean return as the respective global mean.

The weights of each portfolio strategy were derived using a 24-month estimation period. The optimal portfolio weights were then held over the next 24-month period. The performances of four investment strategies were then compared against each other and against that of the Investment Property Databank Monthly Index (IPDMI), which can be considered as the average-mix (market weight) consensus performance of investors in the real estate, for period 2-6.

To evaluate relative performance of each real estate investment strategy the Sharpe performance index, $\left(\mu-\mathrm{R}_{\mathrm{f}}\right) / \sigma$, i.e. the ratio of mean excess return to standard deviation is used. In conducting the tests, the risk-free interest rate, $R_{\mathrm{f}}$ is set to zero. The significance of the difference in Sharpe performance of any two portfolios a and b can then be tested following Z statistic, Jobson and Korkie (1981):

$$
\mathrm{Z}=\frac{\sigma_{\mathrm{a}}\left(\mu_{\mathrm{b}}-\mathrm{R}_{\mathrm{f}}\right)-\sigma_{\mathrm{b}}\left(\mu_{\mathrm{a}}-\mathrm{R}_{\mathrm{f}}\right)}{\sqrt{\Theta}}
$$

where: $\mu_{\mathrm{a}}, \mu_{\mathrm{b}}$ are the mean returns of portfolios $a$ and $b$ and $\sigma_{\mathrm{a}}, \sigma_{b}$ and $\sigma_{a b}$ are estimates of the standard deviation and covariance's of the excess returns of the two portfolios over the evaluation period and where $\Theta$ is calculated as follows:

$$
\Theta=\frac{1}{\mathrm{~T}}\left[2 \sigma_{\mathrm{a}}^{2} \sigma_{\mathrm{b}}^{2}-2 \sigma_{\mathrm{a}} \sigma_{\mathrm{b}} \sigma_{\mathrm{ab}}+\frac{1}{2} \mu_{\mathrm{a}}^{2} \sigma_{\mathrm{b}}^{2}+\frac{1}{2} \mu_{\mathrm{b}}^{2} \sigma_{\mathrm{a}}^{2}-\frac{\mu_{\mathrm{a}} \mu_{\mathrm{b}}}{2 \sigma_{\mathrm{a}} \sigma_{\mathrm{b}}}\left(\sigma_{\mathrm{ab}}^{2}+\sigma_{\mathrm{a}}^{2} \sigma_{\mathrm{b}}^{2}\right)\right]
$$

where $\mathrm{T}$ is the number of observations. Jobson and Korkie (1981) showing that the test statistic $\mathrm{Z}$ is approximately normally distributed with a zero mean and a unit standard 
deviation for large samples. A significant $\mathrm{Z}$ statistics would reject the null hypothesis of equal risk-adjusted performance and would suggest that one of the investment portfolio strategies outperforms the other. Note that the statistical power of the test is low: for a 5\% significance level, it fails to reject a false null $85 \%$ of time (Jorion 1985). Thus observing a statistically significant $\mathrm{Z}$ score between two portfolios can be seen as a strong evidence of a difference in risk-adjusted performance.

\section{Data}

The data used in this study are the monthly total returns for the three sectors: Office, Retail and Industrial property. The property sector data divided into three 'super regions': London, the rest of Southern England and "the North" (the remaining peripheral areas). Eichholtz et al (1995) argues that such a three-property type and three 'super regional' classification provides a viable portfolio investment strategy for investors in the UK. In addition limiting the number of sector/regions to nine is also done to minimise optimisation errors with semi-definite matrices, as the number of observations used in estimating the portfolio parameters was only 24 . The data covering the period 1987:1 to $1998: 12$, a total of 144 observations, broken down into six 24-month periods, the summary statistics of which are presented in Table 1 .

As is to be expected the sector/region that performs 'best' in each period changes from sub-period to sub-period. For example in period 1, 1987: 1 to 1988:12, the highest returns were earned in Industrial properties with the lowest risk achieved in the Retail sector, especially the further away from London in both cases. In contrast in period 5, 1995:1 to 1996:12, the highest returns were achieved in the Retail sector and the lowest risk displayed by Offices, both in London. The data thus showing a degree of risk and return instability found in other studies. Indeed statistical tests of the data, not shown here, reject stationarity in the mean return vector and the variance/covariance matrix in practically all sub-periods, both adjacent and non-adjacent (see Lee, 1998 for an explanation of the tests). Consequently it would be no surprise that ex-post efficient portfolios perform badly in subsequent periods.

\section{Empirical Analysis}

The estimated allocations obtained in this study are displayed in Charts 1 through 5. It can be seen that across all five alternative strategies, there is a high degree of instability in the allocations, with large movements between the different sectors. In addition, there are quite substantial differences between the different approaches. It is however clear that the use of the Bayes-Stein approach, and even more so, the minimum-variance portfolio, does see a reduction in the magnitude of the extreme movements that clearly occur within the classical tangency approach.

The empirical analysis undertaken in this study then examines the potential impact of estimation error. To assess the relative importance of errors in the mean, variance and covariance inputs, we use a similar methodology to that adopted by Chopra \& Ziemba (1993) and Stevenson (2000a). Assuming that the historical estimates are the true 
population figures we estimate a base efficient portfolio. To assess the impact of estimation error in the mean, we replace the historical estimate $\overline{\mathrm{r}}_{\mathrm{i}}$ for asset $i$ with $\overline{\mathrm{r}}_{\mathrm{i}}\left(1+\mathrm{kz} \mathrm{i}_{\mathrm{i}}\right)$, where $k$ is allowed to vary between 0.05 to 0.30 to assess the impact of different magnitudes of errors and $z$ has a standard normal distribution. Similar corrections are then performed with respect to the variance and covariance. In each case the remaining two parameters are left unaltered, while the procedure is completed 100 times for each value of $k$ for a different set of $z$ values. The mean absolute difference from the historical estimates is then calculated for each value of $k$. Table 2 shows the results and it is immediately apparent that the mean is potentially responsible for a far greater degree of error than the two risk parameters. Whereas changes with the variance and covariance have minimal impacts on the performance of the optimal portfolios, at an error equal to $k=0.3$, the mean results in a mean absolute difference of $33.12 \%$. Not only does these findings confirm studies such as Chopra \& Ziemba (1993) with regard to equities and Stevenson (2000a), who analysed real estate securities, but there also support the decision to examine the ex-ante performance of the minimum-variance portfolio. As stated earlier, the attraction of analysing such a strategy is that the allocations are determined purely by the two risk parameters.

Table 3 provides details of the initial empirical analysis of ex-ante performance. The results show the out-of-sample performance of the various alternative strategies, over a two-year horizon. The results are shown for each of five two-year periods, thus the results for period 2, are for those portfolios based on data for 1987 and 1988, with their performance in 1989 and 1990. The results for the overall sample period are also displayed. Table 2 promotes the following comments. First if we consider the overall results it is clear that all the investment strategies, with the exception of Bayes-Stein III, offered greater returns than the IPDMI, but by no more than 10 basis points per month. In addition in all but one case (Bayes-Stein II) the investment strategies offered these increased returns at lower risk. Consequently all strategies achieved higher risk-adjusted performance than the benchmark of market performance in the long run. In contrast none of the investment strategies produced higher returns than the naï ve portfolio. However, the investment strategies all showed lower risk and consequently higher risk adjusted performance. This performance however is not consistent across all sub-periods. In particular in Period 2 the naï ve portfolio and the consensus benchmark showed considerably higher returns with only limited increase in risk and consequently vastly superior risk adjusted performance than all the investment strategies. This may be due the fact that the portfolio weights used in Period 2 are based on the returns in Period 1, which as Table 1 shows corresponds with the market boom. Period 2 in contrast covers the start of the market decline thus the portfolio weights based on a boom period failed badly in a market decline confirming the results of Mueller and Laposa (1995), Meyer and Webb (1991) and Pagliari, et al (1995). However, in Period 3 all the investment strategies show greater return performance than the naï ve portfolio and the market benchmark (IPDMI), as the portfolio weights (based on the performance of Period 2) are now reflecting the market decline. This reflects the fact that the naï ve portfolio contains both good and bad market segments, whereas the alternative strategies will be holding little or nothing in these segments. In the later periods the different investment strategies tend to produce results comparable with both benchmarks with no one strategy proving superior in all periods. 
Secondly the results of the Jobson and Korkie tests, detailed in Table 3, indicate that there is no significant difference in risk-adjusted performance between any of the different investment strategies and the benchmarks of performance. However this is not too surprising as Jobson and Korkie (1981) and Jorion (1985) both note that the test does not have strong power and significant results are unusual.

Finally two clear differences can be found between the results here and those studies which have examined similar strategies in equity and fixed income securities. Previous studies, such as Jorion (1985), Chopra, Hensel \& Turner (1993) and Stevenson (1999, 2000a), have found similar results in that the classical tangency portfolios performs worst ex-ante, and while the use of Bayes-Stein estimators does lead to improvements in performance, the best performance comes from the minimum-variance strategy. These findings are however, not confirmed by the current study and are consistent with the findings of Stevenson (2000c) in his analysis of the American real estate market. None of the alternative strategies consistently outperform the naï ve or market benchmarks, indeed in the individual periods the minimum variance portfolio tends to perform worse than either of the benchmarks and the alternative tangency portfolios. In only one time period, 1989-1990 constructed using 1987-1988 data, does the MVP portfolio outperform on a risk-adjusted basis, any of the other strategies. In contrast, in each of the five individual periods the Sharpe tangency portfolio performs the best of the alternative strategies, although, in line with previous real estate studies, it generally still fails to outperform either of the two benchmarks.

The contrast with the findings from the capital markets is apparent. The attractiveness of the minimum-risk strategy and the poor performance of the classical tangency approach have been linked to the financial economics literature on contrarian strategies and mean reversion (Richards, 1997 and Stevenson, 1999, 2000a). However, due to the differing characteristics of real estate in comparison to capital market assets, and in particular property's cyclical nature, it would be unlikely that performance could reverse over such short holding periods. This cyclical nature may also be responsible for the strong performance of the tangency portfolios, and in particular the classical Sharpe portfolio, which may be due to a momentum effect in property, which would again tend to last longer than corresponding effects in the equity or bonds markets.

The results in Table 3 supposes that investors will only evaluate their portfolio every two years, whereas it seems more reasonable to assume that the fund manger will monitor their portfolios more frequently. This section, therefore, reassess the performance of the ex-post investment strategies on a rolling basis. In other words a second analysis was performed with a rolling 24-month estimation period every three, six and twelve months. The use of different re-estimation periods it is hoped will give an indication of the trade-off of more frequent portfolio reviews against transaction costs. That is more frequent re-estimation should provide greater portfolio performance while the longer review periods will minimise transaction costs.

The results in Table 5 like Table 3 show a number of features of interest. First as the review period decreases the return performance improves, as is to be expected, but not by any significant amount. For example the returns of the Bayes-Stein II strategy do not change 
from the three to six month review periods and only declines by 30 basis points to $0.72 \%$ per month for the yearly review. Indeed for the two-year review period shown in Table 3 the returns once again increase to $0.73 \%$ per month. Similar results can be seen for the other strategies. In addition reducing the review period as little or no impact in reducing portfolio risk. Indeed there is generally a slight increase in risk the greater the frequency of review. This implies that increasing the frequency of the review period as little impact on risk-adjusted return performance. Thus any benefit from more frequent reviews would be easily eliminated by increased transaction costs.

Secondly as seen in Table 3 there are marked differences in performance in the sub-periods, especially in Periods 2 and 3. Once again all the investment strategies generally show poor performance in Period 2 especially against the naï ve portfolio with the switch from boom to decline. But as expected this is less so for the three-month review strategy, as such an approach will be reacting more quickly to the market change. Consequently the longer the review the worse the performance. In Period 3 as suggested by the results in Table 2 with the exception of the MVP strategy, for the three-monthly review period, all the alternative investment strategies now not only out perform the IPDMI benchmark but also show better performance than the naï ve strategy.

Finally in line with the results in Table 3 the MVP investment strategy tends to underperform, while the tangency portfolios tend to outperform other strategies, however, not the two benchmarks ${ }^{2}$. The results also provide further support to the argument that the reason that the MVPs performs so well in the equity and fixed income markets is due to the picking of contrarian effects, while the more long term nature of real estate cycles, means that such a strategy has little advantages over such short horizons. The results also support the findings of Stevenson (2000c) in his analysis of the NCREIF indices in the United States. This study found that out-performance only occurred at longer horizons of around five years, at which point the MVP approach started to out-perform both the tangency portfolios and the benchmark indices.

\section{Conclusions}

Madura and Abernathy (1986) conclude that there is a vast difference between "potential gains" from an ex-post analysis and "realised gains" from an ex-ante analysis. This is true for equity, fixed income and securitised real estate portfolios alike and is confirmed in this study for the direct real estate market. However, techniques such as Bayes-Stein estimation and the use of the MVP, which have yielded promising ex-ante results in capital market studies, are not completely successful in improving out-of-sample performance in this case. It is hypothesised that such results are due to the cyclical nature of property and that the contrarian and mean-reversion effects picked up in studies of stocks and bonds are not captured when an asset such as direct property is examined. This conclusion is also supported by the strong performance of the tangency portfolios, and in particular the classical unadjusted Sharpe portfolio, over the shorter horizons, which would be consistent with a cyclical momentum effect.

\footnotetext{
${ }^{2}$ The Jobson \& Korkie statistics are contained in the appendix for the three holding periods and as with the two-year analysis, are mostly insignificant.
} 
Possible extensions of this work would be investigate the effect of shortening the ex-post time horizon over which the portfolio weights are estimated thereby hopefully making the results more sensitive to recent market conditions. This approach, however, has the disadvantage that the number of time periods used to estimate the portfolio inputs will be less than the number of asset classes leading to problems of rank in the covariance matrix and the inadmissibility of its use in the optimisation, see Ong and Ranasinghe (2000). However, recently Ledoit (1999) has developed a flexible Stein based estimation method that not only allows for the covariance matrix too be calculated in the face of such a situation but significantly improves the sample covariance estimation and the stability of MPT optimisation. In addition recent unpublished research by one the authors (Lee, 2000) suggests that a number of return-weighting schemes that gives greater weight to the most recent data can be used within the portfolio context with good results in ex-ante performance, without reducing the estimation period. In particular it was found that not only did the adaptive-weighted returns out perform the IPDMI benchmark portfolio but showed greater performance than both the unweighted return approach and the naively constrained portfolio. Incorporating these adaptive weighted-returns into the Bayes-Stein approach therefore may improve the ex-ante performance of these investment strategies, especially as the market moves from boom to bust.

The analysis could also be extend by taking into consideration the effects of transaction costs and taxes on the gains from diversification within the real estate portfolio. The issue of transaction costs is of particular importance when one is concerned with a rolling strategy as used in this study. However, the result above in Table 5 indicate that there is little benefit to be gained by reducing the review period and so increasing the transaction costs. Furthermore, in order to robustly analyse the transaction cost issue would involve the incorporation of a number of assumptions concerning investor behaviour. In particular it would be necessary to examine in detail the most appropriate holding period for real estate and to accurately assess realistic costs, which to a large degree would be guided by the issue of illiquidity. The illiquid nature of real estate means that assumptions would have to be made concerning the level of movement that would be allowed within each specified holding period. For example, in the rolling analysis it would be totally unrealistic to assume that changes in the allocations could occur immediately, especially with the one-year analysis. It would therefore, be required to place further restrictions on the percentage change that would be feasible within the specified holding period and to assume that such a change occurred gradually over the same period. If the analysis were to be extended into a multiasset scenario then further issues would arise, such as the different holding periods the assets are held over and the issue of time diversification, which remains a controversial subject itself within the finance literature. However, the result above in Table 5 indicate that there is little benefit to be gained by reducing the review period and so increasing the transaction costs. 


\section{References}

Best, M. and Grauer, R. (1991) On the Sensitivity of Mean Variance Efficient Portfolios to Changes in Asset Means: Some Analytical and Computational Results, Review of Financial Studies, 4, 315-342.

Chopra, V.K. (1993) Mean-Variance Revisited: Near Optimal Portfolios and Sensitivity to Input Variations, Journal of Investing.

Chopra, V.K., Hensel, C.R. and Turner, A.L. (1993) Massaging Mean Variance Inputs: Returns form Alternative Global Investment Strategies in the 1980's, Management Science, 39, 845-855.

Chopra, V.K. and Ziemba, W.T. (1993) The Effect of Errors in Means, Variances and Covariances on Optimal Portfolio Choice, Journal of Portfolio Management, Winter, 6-11.

Effron, B. and Morris, C. (1973) Stein's Estimation Rule and Its Competitors: An Empirical Bayes Approach, Journal of the American Statistical Association, 68, 117-130.

Effron, B. and Morris, C. (1975) Data Analysis using Stein's Estimator and its Generalizations, Journal of the American Statistical Association, 70, 311-319.

Eichholtz, P. M. A., Hoesli, M., MacGregor, B. D. and Nanthakumaran, N. (1995) Real Estate Diversification by Property-type and Region, Journal of Property Finance, 6, 3, 3962.

Eun, C.S. and Resnick, B.G. (1988) Exchange Rate Uncertainty, Forward Contracts, and International Portfolio Selection, Journal of Finance, 43 (March), 197-215.

Frost, P.A. and Savarino, J.E. (1988) For Better Performance: Constrain Portfolio Weights, Journal of Portfolio Management, Fall, 29-34.

Jobson, I.D. and Korkie, B.M. (1981) Performance Hypothesis Testing with the Sharpe and Treynor Measures, Journal of Finance, 36 (September), 544-54.

Jobson, J.D., Korkie, B. and Ratti, V. (1979) Improved Estimation for Markowitz Portfolios using James-Stein Type Estimators, Proceedings of the American Statistical Association, Business and Economics Statistics Section, Washington: American Statistical Association.

Jorion, P. (1985) International Portfolio Diversification with Estimation Risk, Journal of Business, 58, 259-278.

Jorion, P. (1986) Bayes-Stein Estimators for Portfolio Analysis, Journal of Financial and Quantitative Analysis, 21, 279-292.

Jorion, P. (1992) Portfolio Optimisation in Practice, Financial Analysts Journal, JanuaryFebruary, 68-74.

Kalberg, J.G. and Ziemba, W.T. (1984) Mis-Specification in Portfolio Selection Problems, in Bamberg, G. and Spremann, A. (eds.) Risk and Capital, Springer-Verlag: New York. 
Kwok, C.C.Y. (1990) The Numeraire Problem, Forward Hedges, and International Portfolio Selection, Global Finance Journal, 1, 2, 95-20.

Ledoit, O. (1999) Improved Estimation of the Covariance Matrix of Stock Returns with an Application to Portfolio Selection, presented at the Institute for Quantitative Research INQUIRE Conference, Edinburgh, March

Lee, S. L. (1992) Emerging Concepts for the Management of Portfolios and the Role of Research, Property in the Portfolio Context, Society of Property Researchers, London.

Lee, S. L. (1998) The Inter-Temporal Stability of Real Estate Returns: An Empirical Investigation, Working Papers in Land Management and Development, 04/98, pp. 23.

Lee, S. L. (2000) Weighted Returns and Portfolio Optimisation, Unpublished.

Lee, S.L. and Byrne, P. (1998) Diversification by Sector, Region or Function? A Mean Absolute Deviation Optimisation, Journal of Property Valuation \& Investment, 16, 1, 38-56.

Madura, J. and Abernathy, G. (1985). Playing the International Stock Diversification Game with an Unmarked Deck, Journal of Business Research, 13, 465-71.

Markowitz, H. M. (1952) Portfolio Selection, Journal of Finance, 7, 1, 77-91.

Michaud, R. O. (1989) The Markowitz Optimisation Enigma: is 'Optimized' Optimal? Financial Analysts Journal, January/February, 31-42.

Michaud, R. O. (1998) Efficient Asset Management, Harvard Business School Press, Boston Massachusetts, USA.

Morrell, G.D. (1993) Value-weighting and the Variability of Real Estate Returns: Implications for Portfolio Construction and Performance Evaluation, Journal of Property Research, 10, 167-183.

Mueller, G. R. and Laposa, S. P. (1995) Property-Type Diversification in Real Estate Portfolios: Size and Return Perspective, The Journal of Real Estate Portfolio Management, 1,1, 39-50.

Myer, F.C.N. and Webb, J.R. (1991) Estimating Allocations for Mixed-Asset Portfolios Using the Bootstrap Technique. Paper presented at the American Real Estate Society Meeting, Sarasota, Florida.

Ong, S. and Ranasinghe, M. (2000) Portfolio Variance and Correlation Matrices, Journal of Real Estate Portfolio Management, 6, 1, 1-6.

Pagliari, J. L., Webb, J. R. and Del Casino, J. J. (1995) Applying MPT to Institutional Real Estate Portfolios: The Good the Bad and the Uncertain, The Journal of Real Estate Portfolio Management, 1, 67-88.

Richards, A.J. (1997). Winner-Loser Reversals in National Stock Indices: Can They be Explained ?, Journal of Finance, 52, 2129-2144. 
Sharpe, W.F. (1966) Mutual Fund Performance, Journal of Business, 39, (Jan), 119-138.

Sharpe, W. F. (1994) The Sharpe Ratio, Journal of Portfolio Management, Fall, 49-58.

Stein, C. (1955) Inadmissibility of the Usual Estimator for the Mean of a Multivariate Normal Distribution, Proceedings of the $3^{\text {rd }}$ Berkeley Symposium on Probability and Statistics, University of California Press: Berkeley, CA.

Stevenson, S. (1999) Emerging Markets, Downside Risk \& the Asset Allocation Decision, Paper presented at the Financial Management Association annual conference, Orlando, Florida.

Stevenson, S. (2000a) Bayes-Stein Estimators and International Real Estate Asset Allocation, Paper presented at the Pacific-Rim Real Estate Society annual meeting, Sydney, Australia and the American Real Estate Society annual meeting, Santa Barbara, California.

Stevenson, S. (2000b) Constraining Optimal Portfolios \& The Effect on Real Estates Allocation, Journal of Property Investment \& Finance, forthcoming.

Stevenson, S. (2000c) The Out-of-Sample Performance of Optimal Portfolios: Empirical Tests with the NCREIF, Paper presented at the American Real Estate Society annual meeting, Santa Barbara, California.

Table: 1 The Risk and Return Characteristics of Sector and Regional Indices Per cent per Month 1987:1 to 1998:12

\begin{tabular}{lccccccccccccc}
\hline Period & \multicolumn{3}{c}{ Period 1 } & \multicolumn{1}{c}{ Period 2 } & \multicolumn{2}{c}{ Period 3 } & \multicolumn{2}{c}{ Period 4 } & \multicolumn{2}{c}{ Period 5 } & \multicolumn{2}{c}{ Period 6 } \\
\cline { 2 - 12 } Sector/Region & Mean & SD & Mean & SD & Mean & SD & Mean & SD & Mean & SD & Mean & SD \\
\hline Retail & & & & & & & & & & & & \\
London & 1.88 & 1.11 & 0.02 & 0.83 & 0.06 & 0.45 & 1.16 & 0.96 & 0.66 & 0.40 & 1.27 & 0.53 \\
South East & 1.41 & 0.77 & 0.08 & 0.90 & 0.28 & 0.48 & 1.23 & 0.99 & 0.34 & 0.39 & 0.92 & 0.35 \\
Rest of UK & 1.37 & 0.57 & 0.11 & 0.77 & 0.42 & 0.42 & 1.43 & 1.01 & 0.54 & 0.34 & 1.11 & 0.38 \\
Office & & & & & & & & & & & & \\
London & 2.20 & 1.03 & 0.17 & 1.34 & -1.13 & 0.57 & 1.02 & 0.98 & 0.64 & 0.30 & 1.18 & 0.47 \\
South East & 1.68 & 1.26 & 0.47 & 1.39 & -0.49 & 0.39 & 1.10 & 1.14 & 0.41 & 0.43 & 1.16 & 0.31 \\
Rest of UK & 1.88 & 1.27 & 1.33 & 1.77 & 0.08 & 0.48 & 1.10 & 1.06 & 0.39 & 0.32 & 0.82 & 0.28 \\
Industrial & & & & & & & & & & & & \\
London & 2.14 & 1.54 & 0.76 & 1.63 & 0.30 & 0.59 & 1.16 & 1.01 & 0.62 & 0.31 & 1.30 & 0.41 \\
South East & 2.39 & 1.00 & 0.82 & 1.26 & 0.07 & 0.62 & 1.03 & 0.86 & 0.52 & 0.41 & 1.24 & 0.34 \\
Rest of UK & 2.49 & 1.31 & 1.13 & 1.43 & 0.68 & 0.53 & 1.54 & 1.18 & 0.52 & 0.35 & 0.98 & 0.29 \\
\hline
\end{tabular}


Chart 1: Classical Tangency Allocations

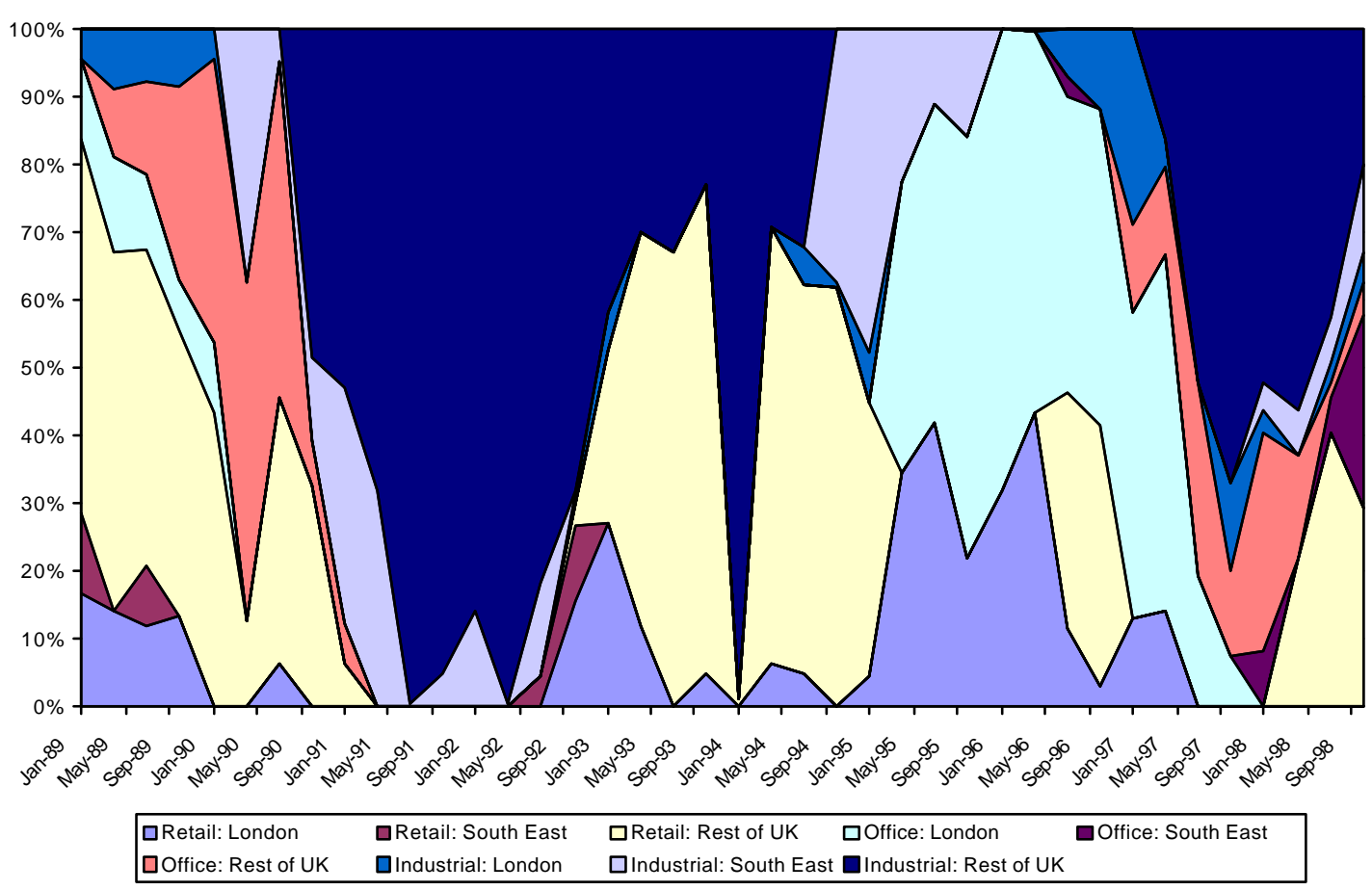

Chart 2: Bayes-Stein I Allocations

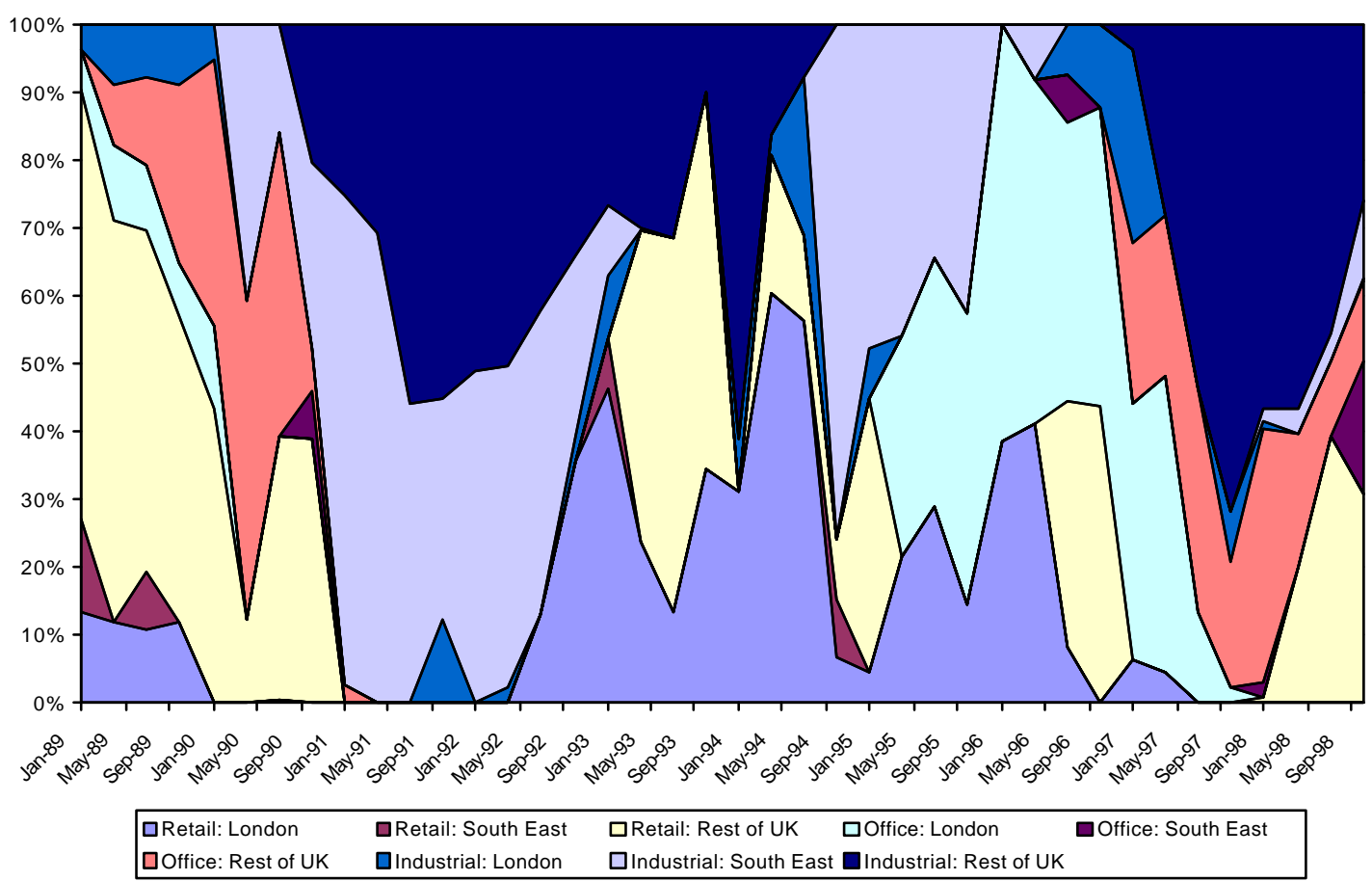


Chart 3: Bayes-Stein II Allocations

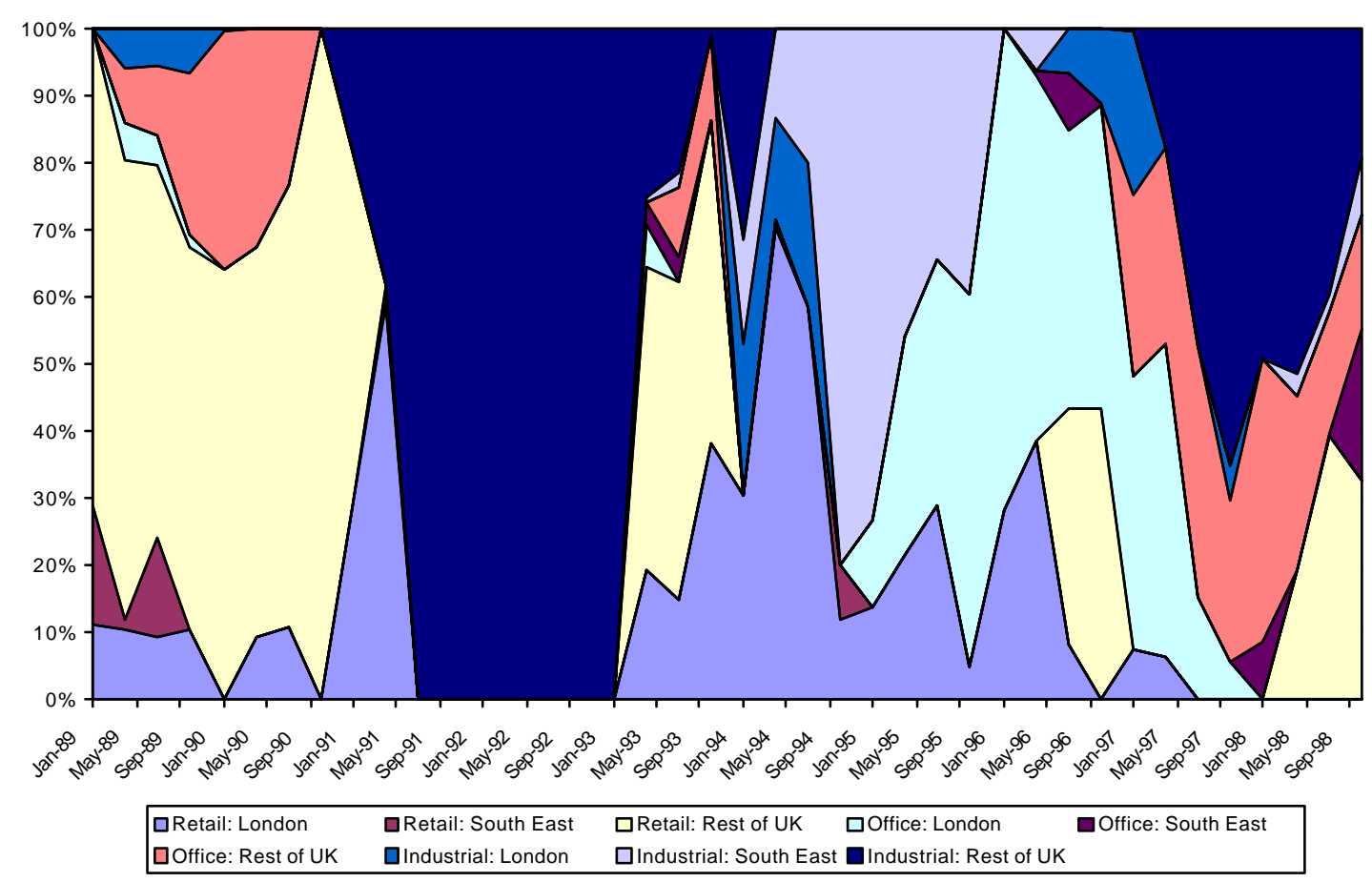

Chart 4: Bayes-Stein III Allocations

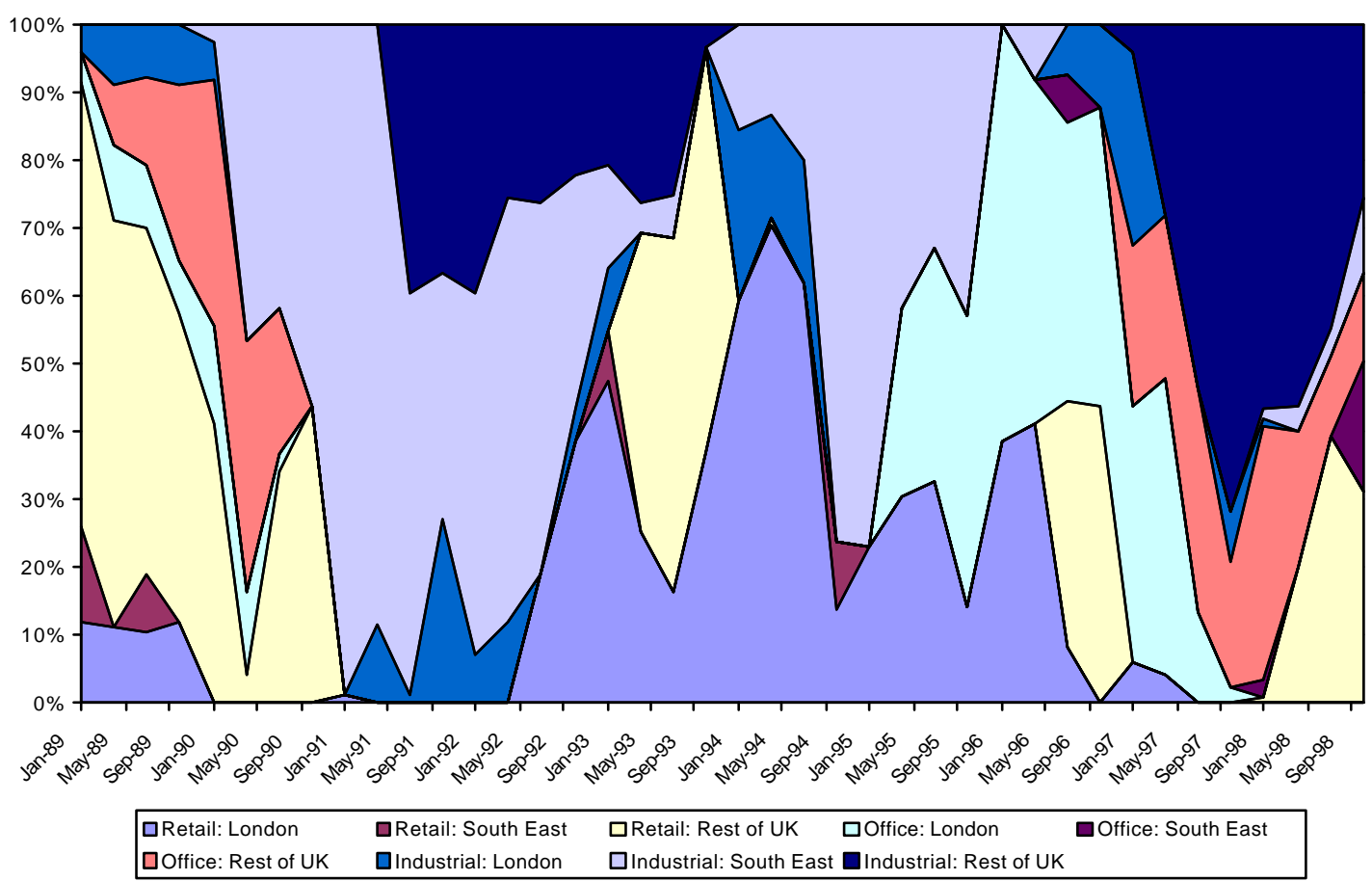




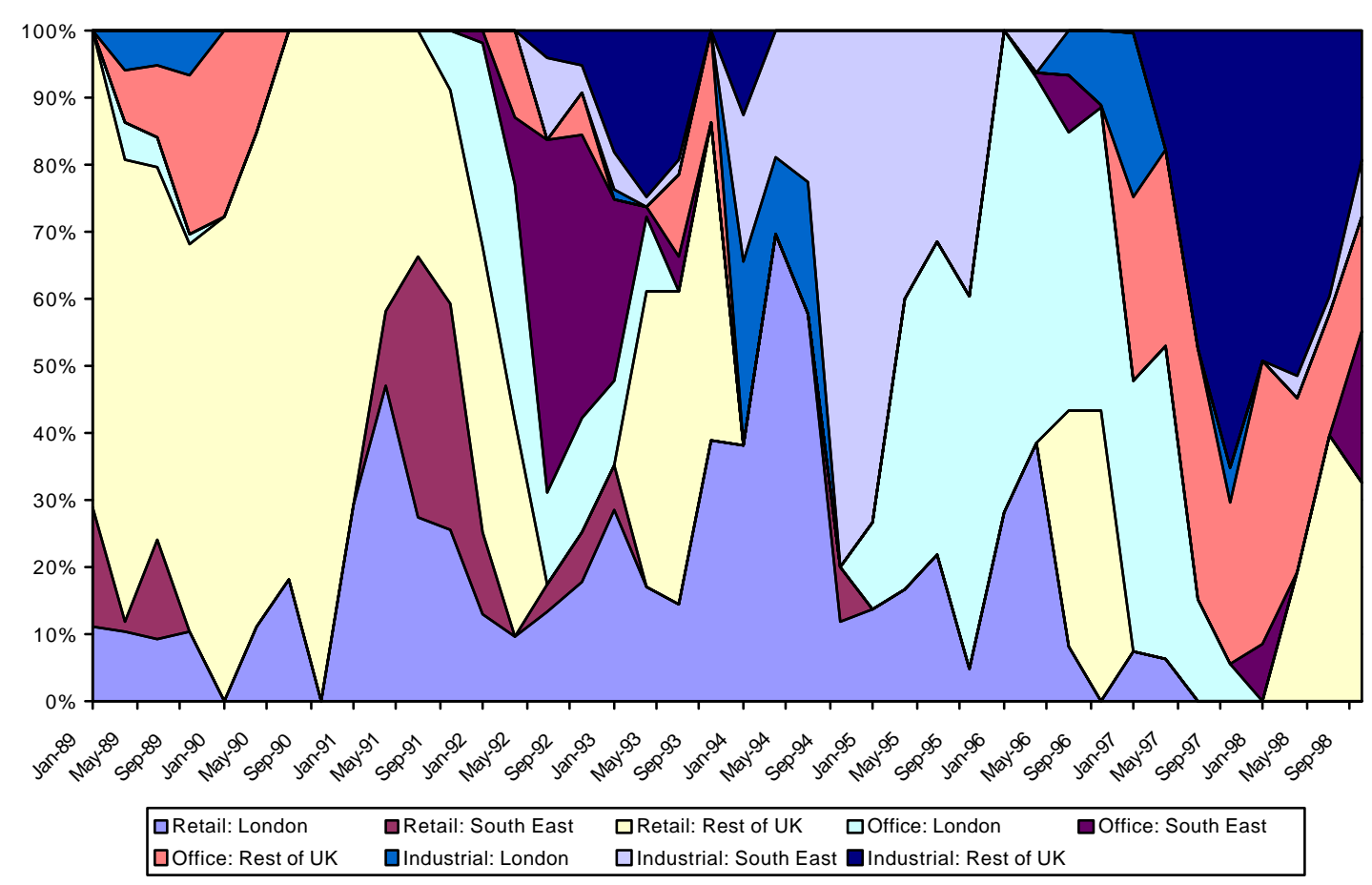

Table 2: Impact of Estimation Error

\begin{tabular}{cccc} 
& \multicolumn{2}{c}{$\begin{array}{c}\mathbf{Z}= \\
\text { Means } \\
\text { Variances } \\
\text { Covariance } \\
\text { s }\end{array}$} \\
\hline 0.05 & $5.52 \%$ & $0.16 \%$ & $0.04 \%$ \\
0.10 & $11.04 \%$ & $0.26 \%$ & $0.07 \%$ \\
0.15 & $16.56 \%$ & $0.44 \%$ & $0.11 \%$ \\
0.20 & $22.08 \%$ & $0.72 \%$ & $0.19 \%$ \\
0.25 & $27.60 \%$ & $1.19 \%$ & $0.30 \%$ \\
0.30 & $33.12 \%$ & $1.96 \%$ & $0.48 \%$ \\
\hline
\end{tabular}


Table 2: Risk Return Performance

\begin{tabular}{|c|c|c|c|}
\hline & Return & Risk & Sharpe Ratio \\
\hline \multicolumn{4}{|l|}{ Period 2} \\
\hline Sharpe & 0.17 & 0.97 & 0.17 \\
\hline Bayes-Stein I & 0.12 & 0.83 & 0.15 \\
\hline Bayes-Stein II & 0.10 & 0.78 & 0.12 \\
\hline Bayes-Stein III & 0.12 & 0.82 & 0.15 \\
\hline MVP & 0.09 & 0.78 & 0.12 \\
\hline Naive & 0.54 & 1.18 & 0.46 \\
\hline Market & 0.38 & 1.08 & 0.35 \\
\hline \multicolumn{4}{|l|}{ Period 3} \\
\hline Sharpe & 0.41 & 0.46 & 0.90 \\
\hline Bayes-Stein I & 0.22 & 0.53 & 0.42 \\
\hline Bayes-Stein II & 0.36 & 0.35 & 1.02 \\
\hline Bayes-Stein III & 0.07 & 0.62 & 0.11 \\
\hline MVP & 0.33 & 0.37 & 0.89 \\
\hline Naive & 0.03 & 0.32 & 0.09 \\
\hline Market & -0.03 & 0.33 & -0.1 \\
\hline \multicolumn{4}{|l|}{ Period 4} \\
\hline Sharpe & 1.39 & 1.03 & 1.34 \\
\hline Bayes-Stein I & 1.26 & 0.97 & 1.29 \\
\hline Bayes-Stein II & 1.54 & 1.18 & 1.31 \\
\hline Bayes-Stein III & 1.23 & 0.96 & 1.28 \\
\hline MVP & 1.20 & 1.00 & 1.20 \\
\hline Naive & 1.20 & 0.97 & 1.24 \\
\hline Market & 1.24 & 0.97 & 1.27 \\
\hline \multicolumn{4}{|l|}{ Period 5} \\
\hline Sharpe & 0.54 & 0.34 & 1.60 \\
\hline Bayes-Stein I & 0.54 & 0.34 & 1.60 \\
\hline Bayes-Stein II & 0.56 & 0.35 & 1.57 \\
\hline Bayes-Stein III & 0.55 & 0.37 & 1.49 \\
\hline MVP & 0.54 & 0.37 & 1.46 \\
\hline Naive & 0.52 & 0.29 & 1.75 \\
\hline Market & 0.51 & 0.31 & 1.63 \\
\hline \multicolumn{4}{|l|}{ Period 6} \\
\hline Sharpe & 1.18 & 0.35 & 3.37 \\
\hline Bayes-Stein I & 1.13 & 0.32 & 3.57 \\
\hline Bayes-Stein II & 1.12 & 0.32 & 3.52 \\
\hline Bayes-Stein III & 1.13 & 0.32 & 3.57 \\
\hline MVP & 1.12 & 0.32 & 3.52 \\
\hline Naive & 1.11 & 0.29 & 3.77 \\
\hline Market & 1.19 & 0.3 & 3.93 \\
\hline \multicolumn{4}{|l|}{ Overall } \\
\hline Sharpe & 0.73 & 0.82 & 1.10 \\
\hline Bayes-Stein I & 0.65 & 0.79 & 1.04 \\
\hline Bayes-Stein II & 0.73 & 0.86 & 1.00 \\
\hline Bayes-Stein III & 0.62 & 0.82 & 0.93 \\
\hline MVP & 0.66 & 0.76 & 1.15 \\
\hline Naive & 0.89 & 0.95 & 0.94 \\
\hline Market & 0.63 & 0.83 & 0.76 \\
\hline
\end{tabular}


Table 3: Jobson-Korkie Statistics for 2 year Holding Periods

\begin{tabular}{|c|c|c|c|c|c|c|}
\hline Period 2 & Market & Naive & MVP & Sharpe & BS I & BS II \\
\hline Naive & -0.1232 & & & & & \\
\hline MVP & 0.2456 & 0.3699 & & & & \\
\hline Sharpe & 0.2136 & 0.3370 & -0.0294 & & & \\
\hline Bayes-Stein I & 0.2165 & 0.3400 & -0.0272 & 0.0021 & & \\
\hline Bayes-Stein II & 0.2448 & 0.3690 & -0.0008 & 0.0285 & 0.0264 & \\
\hline Bayes-Stein III & 0.2135 & 0.3371 & -0.0304 & -0.0011 & -0.0032 & -0.0296 \\
\hline \multicolumn{7}{|l|}{ Period 3} \\
\hline Naive & -0.2150 & & & & & \\
\hline MVP & -1.1546 & -0.9638 & & & & \\
\hline Sharpe & -1.2556 & -0.9309 & -0.0667 & & & \\
\hline Bayes-Stein I & -0.6984 & -0.4003 & 0.8538 & 0.5296 & & \\
\hline Bayes-Stein II & -1.3471 & -1.1319 & -0.1861 & -0.1766 & -1.0368 & \\
\hline Bayes-Stein III & -0.3061 & -0.0248 & 1.8967 & 0.9537 & 0.3385 & $2.0263^{*}$ \\
\hline \multicolumn{7}{|l|}{ Period 4} \\
\hline Naive & 0.0355 & & & & & \\
\hline MVP & 0.0785 & 0.0429 & & & & \\
\hline Sharpe & -0.0791 & -0.1145 & -0.1578 & & & \\
\hline Bayes-Stein I & -0.0208 & -0.0564 & -0.0996 & 0.0579 & & \\
\hline Bayes-Stein II & -0.0459 & -0.0815 & -0.1254 & 0.0342 & -0.0244 & \\
\hline Bayes-Stein III & -0.0154 & -0.0509 & -0.0941 & 0.0634 & 0.0054 & 0.0300 \\
\hline \multicolumn{7}{|l|}{ Period 5} \\
\hline Naive & -0.1301 & & & & & \\
\hline MVP & 0.0674 & 0.1990 & & & & \\
\hline Sharpe & 0.0392 & 0.1684 & -0.0261 & & & \\
\hline Bayes-Stein I & 0.0392 & 0.1684 & -0.0261 & 0.0000 & & \\
\hline Bayes-Stein II & 0.0676 & 0.1992 & 0.0002 & 0.0263 & 0.0263 & \\
\hline Bayes-Stein III & 0.1602 & 0.2887 & 0.0877 & 0.1149 & 0.1149 & 0.0875 \\
\hline \multicolumn{7}{|l|}{ Period 6} \\
\hline Naive & -0.2171 & & & & & \\
\hline MVP & 0.0558 & 0.2762 & & & & \\
\hline Sharpe & 0.2237 & 0.4406 & 0.1634 & & & \\
\hline Bayes-Stein I & 0.0035 & 0.2251 & -0.0499 & -0.2137 & & \\
\hline Bayes-Stein II & 0.0560 & 0.2764 & 0.0002 & -0.1632 & 0.0501 & \\
\hline Bayes-Stein III & -0.0012 & 0.2205 & -0.0545 & -0.2184 & -0.0045 & -0.0547 \\
\hline \multicolumn{7}{|l|}{ Overall } \\
\hline Naive & -0.0578 & & & & & \\
\hline MVP & -0.1125 & -0.0535 & & & & \\
\hline Sharpe & -0.1438 & -0.0848 & -0.0306 & & & \\
\hline Bayes-Stein I & -0.0678 & -0.0082 & 0.0443 & 0.0734 & & \\
\hline Bayes-Stein II & -0.1046 & -0.0447 & 0.0091 & 0.0397 & -0.0351 & \\
\hline Bayes-Stein III & 0.0039 & 0.0642 & 0.1169 & 0.1451 & 0.0694 & 0.1083 \\
\hline
\end{tabular}


Table 4: Rolling Risk Return Performance

\begin{tabular}{|c|c|c|c|c|c|c|c|c|c|}
\hline \multirow[b]{2}{*}{ Period $?$} & \multicolumn{3}{|c|}{ Three-Monthlv Review } & \multicolumn{3}{|c|}{ Six-Monthlv Review } & \multicolumn{3}{|c|}{ Yearlv Review } \\
\hline & Return & Riclk & Sharne & Roturn & Risk & Sharne & Return & Risk & Sharne \\
\hline Market & 0.38 & 1.08 & 0.35 & - & - & - & - & - & - \\
\hline Naï ve & 0.54 & 1.18 & 0.46 & - & - & - & - & - & - \\
\hline MVP & 0.27 & 0.84 & 0.33 & 0.22 & 0.80 & 0.28 & 0.15 & 0.75 & 0.20 \\
\hline Classical & 0.39 & 0.88 & 0.44 & 0.31 & 0.86 & 0.36 & 0.20 & 0.82 & 0.25 \\
\hline Bayes-Stein I & 0.37 & 0.86 & 0.43 & 0.30 & 0.83 & 0.36 & 0.18 & 0.81 & 0.22 \\
\hline Bayes-Stein II & 0.29 & 0.84 & 0.35 & 0.24 & 0.79 & 0.30 & 0.16 & 0.75 & 0.22 \\
\hline Bayes-Stein III & 0.37 & 0.85 & 0.44 & 0.30 & 0.81 & 0.38 & 0.18 & 0.82 & 0.22 \\
\hline \multicolumn{10}{|l|}{ Period 3} \\
\hline Market & -0.03 & 0.33 & -0.10 & - & - & - & - & - & - \\
\hline Naï ve & 0.03 & 0.32 & 0.09 & - & - & - & - & - & - \\
\hline MVP & -0.03 & 0.38 & -0.07 & 0.03 & 0.44 & 0.06 & 0.10 & 0.37 & 0.28 \\
\hline Classical & 0.60 & 0.52 & 1.16 & 0.57 & 0.52 & 1.10 & 0.51 & 0.44 & 1.17 \\
\hline Bayes-Stein I & 0.38 & 0.50 & 0.75 & 0.36 & 0.49 & 0.74 & 0.32 & 0.46 & 0.70 \\
\hline Bayes-Stein II & 0.57 & 0.54 & 1.06 & 0.58 & 0.53 & 1.08 & 0.42 & 0.42 & 0.99 \\
\hline Bayes-Stein III & 0.28 & 0.54 & 0.53 & 0.28 & 0.51 & 0.54 & 0.23 & 0.48 & 0.47 \\
\hline \multicolumn{10}{|l|}{ Period 4} \\
\hline Market & 1.24 & 0.97 & 1.27 & - & - & - & - & - & - \\
\hline Naï ve & 1.2 & 0.97 & 1.24 & - & - & - & - & - & - \\
\hline MVP & 1.24 & 1.07 & 1.16 & 1.26 & 1.04 & 1.21 & 1.22 & 0.99 & 1.23 \\
\hline Classical & 1.52 & 1.22 & 1.25 & 1.54 & 1.21 & 1.27 & 1.47 & 1.19 & 1.23 \\
\hline Bayes-Stein I & 1.36 & 1.16 & 1.17 & 1.39 & 1.14 & 1.22 & 1.32 & 1.07 & 1.23 \\
\hline Bayes-Stein II & 1.33 & 1.07 & 1.24 & 1.38 & 1.04 & 1.34 & 1.41 & 1.02 & 1.38 \\
\hline Bayes -Stein III & 1.25 & 1.04 & 1.21 & 1.26 & 1.01 & 1.24 & 1.18 & 0.93 & 1.27 \\
\hline \multicolumn{10}{|l|}{ Period 5} \\
\hline Market & 0.51 & 0.31 & 1.63 & - & - & - & - & - & - \\
\hline Naï ve & 0.52 & 0.29 & 1.75 & - & - & - & - & - & - \\
\hline MVP & 0.57 & 0.34 & 1.69 & 0.55 & 0.34 & 1.64 & 0.53 & 0.36 & 1.49 \\
\hline Classical & 0.58 & 0.32 & 1.83 & 0.56 & 0.33 & 1.72 & 0.53 & 0.34 & 1.53 \\
\hline Bayes-Stein I & 0.57 & 0.33 & 1.72 & 0.56 & 0.33 & 1.68 & 0.54 & 0.35 & 1.54 \\
\hline Bayes-Stein II & 0.57 & 0.34 & 1.65 & 0.55 & 0.34 & 1.61 & 0.53 & 0.36 & 1.49 \\
\hline Bayes-Stein III & 0.56 & 0.35 & 1.62 & 0.55 & 0.35 & 1.57 & 0.53 & 0.37 & 1.44 \\
\hline \multicolumn{10}{|l|}{ Period 6} \\
\hline Market & 1.09 & 0.30 & 3.57 & - & - & - & - & - & - \\
\hline Naï ve & 1.11 & 0.29 & 3.77 & - & - & - & - & - & - \\
\hline MVP & 0.98 & 0.28 & 3.47 & 0.99 & 0.29 & 3.39 & 1.07 & 0.30 & 3.62 \\
\hline Classical & 1.03 & 0.30 & 3.44 & 1.03 & 0.31 & 3.34 & 1.13 & 0.32 & 3.51 \\
\hline Bayes-Stein I & 0.99 & 0.28 & 3.52 & 0.99 & 0.29 & 3.40 & 1.07 & 0.30 & 3.64 \\
\hline Bayes-Stein II & 0.98 & 0.28 & 3.47 & 0.99 & 0.29 & 3.39 & 1.07 & 0.30 & 3.62 \\
\hline Bayes-Stein III & 0.99 & 0.28 & 3.52 & 0.99 & 0.29 & 3.40 & 1.07 & 0.29 & 3.64 \\
\hline \multicolumn{10}{|l|}{ Overall } \\
\hline Market & 0.63 & 0.83 & 0.76 & - & - & - & - & - & - \\
\hline Naï ve & 0.89 & 0.95 & 0.94 & - & - & - & - & - & - \\
\hline MVP & 0.61 & 0.80 & 0.76 & 0.61 & 0.79 & 0.77 & 0.62 & 0.76 & 0.81 \\
\hline Classical & 0.83 & 0.83 & 0.99 & 0.80 & 0.84 & 0.95 & 0.77 & 0.84 & 0.92 \\
\hline Bayes-Stein I & 0.73 & 0.80 & 0.92 & 0.72 & 0.80 & 0.90 & 0.69 & 0.79 & 0.87 \\
\hline Bayes-Stein II & 0.75 & 0.76 & 0.98 & 0.75 & 0.76 & 0.98 & 0.72 & 0.77 & 0.93 \\
\hline Bayes-Stein III & 0.69 & 0.76 & 0.91 & 0.68 & 0.75 & 0.90 & 0.64 & 0.75 & 0.85 \\
\hline
\end{tabular}




\section{Appendix}

Table A1: Jobson-Korkie Statistics for 3 Month Holding Periods

\begin{tabular}{|c|c|c|c|c|c|c|}
\hline Period 2 & Market & Naive & MVP & Sharpe & BS I & BS II \\
\hline Naive & -0.1232 & & & & & \\
\hline MVP & 0.0230 & 0.1485 & & & & \\
\hline Sharpe & -0.1012 & 0.0252 & -0.1223 & & & \\
\hline Bayes-Stein I & -0.0921 & 0.0337 & -0.1133 & 0.0085 & & \\
\hline Bayes-Stein II & 0.0016 & 0.1276 & -0.0210 & 0.1005 & 0.0918 & \\
\hline Bayes-Stein III & -0.0978 & 0.0271 & -0.1199 & 0.0021 & -0.0065 & -0.0988 \\
\hline \multicolumn{7}{|l|}{ Period 3} \\
\hline Naive & -0.2150 & & & & & \\
\hline MVP & -0.0436 & 0.1926 & & & & \\
\hline Sharpe & -1.6481 & -1.3003 & -1.5483 & & & \\
\hline Bayes-Stein I & -1.0822 & -0.7712 & -0.9871 & 0.4662 & & \\
\hline Bayes-Stein II & -1.6047 & -1.2743 & -1.5998 & 0.1091 & -0.3952 & \\
\hline Bayes-Stein III & -0.8091 & -0.5147 & -0.7440 & 0.7757 & 0.2452 & 0.7414 \\
\hline \multicolumn{7}{|l|}{ Period 4} \\
\hline Naive & 0.0355 & & & & & \\
\hline MVP & 0.1138 & 0.0783 & & & & \\
\hline Sharpe & 0.0229 & -0.0130 & -0.0920 & & & \\
\hline Bayes-Stein I & 0.1046 & 0.0687 & -0.0098 & 0.0811 & & \\
\hline Bayes-Stein II & 0.0277 & -0.0081 & -0.0863 & 0.0049 & -0.0764 & \\
\hline Bayes-Stein III & 0.0701 & 0.0345 & -0.0438 & 0.0479 & -0.0343 & 0.0423 \\
\hline \multicolumn{7}{|l|}{ Period 5} \\
\hline Naive & -0.1301 & & & & & \\
\hline MVP & -0.0665 & 0.0728 & & & & \\
\hline Sharpe & -0.2300 & -0.0881 & -0.1510 & & & \\
\hline Bayes-Stein I & -0.0982 & 0.0387 & -0.0309 & 0.1195 & & \\
\hline Bayes-Stein II & -0.0180 & 0.1187 & 0.0438 & 0.1947 & 0.0747 & \\
\hline Bayes-Stein III & 0.0073 & 0.1425 & 0.0671 & 0.2178 & 0.0979 & 0.0232 \\
\hline \multicolumn{7}{|l|}{ Period 6} \\
\hline Naive & -0.2171 & & & & & \\
\hline MVP & 0.1162 & 0.3492 & & & & \\
\hline Sharpe & 0.1514 & 0.3850 & 0.0323 & & & \\
\hline Bayes-Stein I & 0.0606 & 0.2937 & -0.0502 & -0.0830 & & \\
\hline Bayes-Stein II & 0.1155 & 0.3486 & -0.0006 & -0.0329 & 0.0496 & \\
\hline Bayes-Stein III & 0.0619 & 0.2950 & -0.0490 & -0.0819 & 0.0012 & -0.0485 \\
\hline \multicolumn{7}{|l|}{ Overall } \\
\hline Naive & -0.0578 & & & & & \\
\hline MVP & 0.0003 & 0.0597 & & & & \\
\hline Sharpe & -0.2544 & -0.1939 & -0.2494 & & & \\
\hline Bayes-Stein I & -0.1684 & -0.1085 & -0.1650 & 0.0785 & & \\
\hline Bayes-Stein II & -0.2403 & -0.1798 & -0.2350 & 0.0144 & -0.0648 & \\
\hline Bayes-Stein III & -0.1549 & -0.0956 & -0.1527 & 0.0922 & 0.0118 & 0.0777 \\
\hline
\end{tabular}


Table A2: Jobson-Korkie Statistics for 6 Month Holding Periods

\begin{tabular}{|c|c|c|c|c|c|c|}
\hline Period 2 & Market & Naive & MVP & Sharpe & BS I & BS II \\
\hline Naive & -0.1232 & & & & & \\
\hline MVP & 0.0778 & 0.2025 & & & & \\
\hline Sharpe & -0.0108 & 0.1145 & -0.0875 & & & \\
\hline Bayes-Stein I & -0.0101 & 0.1149 & -0.0866 & 0.0006 & & \\
\hline Bayes-Stein II & 0.0562 & 0.1814 & -0.0215 & 0.0654 & 0.0647 & \\
\hline Bayes-Stein III & -0.0317 & 0.0928 & -0.1080 & -0.0209 & -0.0214 & -0.0865 \\
\hline \multicolumn{7}{|l|}{ Period 3} \\
\hline Naive & -0.2150 & & & & & \\
\hline MVP & -0.2093 & 0.0437 & & & & \\
\hline Sharpe & -1.5758 & -1.2266 & -1.3322 & & & \\
\hline Bayes-Stein I & -1.0684 & -0.7588 & -0.8514 & 0.4060 & & \\
\hline Bayes-Stein II & -1.6088 & -1.2838 & -1.4535 & 0.0223 & -0.4243 & \\
\hline Bayes-Stein III & -0.8244 & -0.5340 & -0.6312 & 0.6650 & 0.2116 & 0.7256 \\
\hline \multicolumn{7}{|l|}{ Period 4} \\
\hline Naive & 0.0355 & & & & & \\
\hline MVP & 0.0689 & 0.0335 & & & & \\
\hline Sharpe & -0.0005 & -0.0363 & -0.0704 & & & \\
\hline Bayes-Stein I & 0.0559 & 0.0201 & -0.0135 & 0.0561 & & \\
\hline Bayes-Stein II & -0.0701 & -0.1057 & -0.1392 & -0.0698 & -0.1258 & \\
\hline Bayes-Stein III & 0.0317 & -0.0039 & -0.0374 & 0.0327 & -0.0241 & 0.1018 \\
\hline \multicolumn{7}{|l|}{ Period 5} \\
\hline Naive & -0.1301 & & & & & \\
\hline MVP & -0.0073 & 0.1283 & & & & \\
\hline Sharpe & -0.0971 & 0.0386 & -0.0849 & & & \\
\hline Bayes-Stein I & -0.0513 & 0.0827 & -0.0416 & 0.0429 & & \\
\hline Bayes-Stein II & 0.0211 & 0.1550 & 0.0263 & 0.1112 & 0.0681 & \\
\hline Bayes-Stein III & 0.0699 & 0.2015 & 0.0721 & 0.1566 & 0.1134 & 0.0456 \\
\hline \multicolumn{7}{|l|}{ Period 6} \\
\hline Naive & -0.2171 & & & & & \\
\hline MVP & 0.2196 & 0.4537 & & & & \\
\hline Sharpe & 0.2828 & 0.5175 & 0.0559 & & & \\
\hline Bayes-Stein I & 0.2115 & 0.4460 & -0.0077 & -0.0636 & & \\
\hline Bayes-Stein II & 0.2191 & 0.4532 & -0.0004 & -0.0563 & 0.0072 & \\
\hline Bayes-Stein III & 0.2121 & 0.4465 & -0.0072 & -0.0631 & 0.0004 & -0.0068 \\
\hline \multicolumn{7}{|l|}{ Overall } \\
\hline Naive & -0.0578 & & & & & \\
\hline MVP & -0.0076 & 0.0520 & & & & \\
\hline Sharpe & -0.2105 & -0.1500 & -0.1975 & & & \\
\hline Bayes-Stein I & -0.1456 & -0.0859 & -0.1348 & 0.0587 & & \\
\hline Bayes-Stein II & -0.2387 & -0.1783 & -0.2244 & -0.0253 & -0.0849 & \\
\hline Bayes-Stein III & -0.1451 & -0.0859 & -0.1351 & 0.0591 & -0.0007 & 0.0851 \\
\hline
\end{tabular}


Table A3: Jobson-Korkie Statistics for 1 Year Holding Periods

\begin{tabular}{|c|c|c|c|c|c|c|}
\hline Period 2 & Market & Naive & MVP & Sharpe & BS I & BS II \\
\hline Naive & -0.1232 & & & & & \\
\hline MVP & 0.1642 & 0.2890 & & & & \\
\hline Sharpe & 0.1078 & 0.2329 & -0.0551 & & & \\
\hline Bayes-Stein I & 0.1362 & 0.2613 & -0.0271 & 0.0278 & & \\
\hline Bayes-Stein II & 0.1428 & 0.2684 & -0.0216 & 0.0333 & 0.0054 & \\
\hline Bayes-Stein III & 0.1439 & 0.2688 & -0.0191 & 0.0357 & 0.0079 & 0.0025 \\
\hline \multicolumn{7}{|l|}{ Period 3} \\
\hline Naive & -0.2150 & & & & & \\
\hline MVP & -0.4724 & -0.2226 & & & & \\
\hline Sharpe & -1.5884 & -1.2674 & -1.1557 & & & \\
\hline Bayes-Stein I & -1.0037 & -0.7087 & -0.5559 & 0.5396 & & \\
\hline Bayes-Stein II & -1.4059 & -1.1595 & -1.0090 & 0.2224 & -0.4430 & \\
\hline Bayes-Stein III & -0.7397 & -0.4595 & -0.2787 & 0.8632 & 0.2465 & 0.8937 \\
\hline \multicolumn{7}{|l|}{ Period 4} \\
\hline Naive & 0.0355 & & & & & \\
\hline MVP & 0.0449 & 0.0093 & & & & \\
\hline Sharpe & 0.0458 & 0.0095 & 0.0001 & & & \\
\hline Bayes-Stein I & 0.0396 & 0.0035 & -0.0059 & -0.0059 & & \\
\hline Bayes-Stein II & -0.1132 & -0.1483 & -0.1583 & -0.1599 & -0.1537 & \\
\hline Bayes-Stein III & -0.0013 & -0.0370 & -0.0462 & -0.0471 & -0.0407 & 0.1119 \\
\hline \multicolumn{7}{|l|}{ Period 5} \\
\hline Naive & -0.1301 & & & & & \\
\hline MVP & 0.1611 & 0.2909 & & & & \\
\hline Sharpe & 0.1086 & 0.2360 & -0.0467 & & & \\
\hline Bayes-Stein I & 0.0967 & 0.2238 & -0.0585 & -0.0115 & & \\
\hline Bayes-Stein II & 0.1613 & 0.2911 & 0.0002 & 0.0468 & 0.0586 & \\
\hline Bayes-Stein III & 0.2162 & 0.3413 & 0.0535 & 0.1001 & 0.1116 & 0.0534 \\
\hline \multicolumn{7}{|l|}{ Period 6} \\
\hline Naive & -0.2171 & & & & & \\
\hline MVP & -0.0539 & 0.1743 & & & & \\
\hline Sharpe & 0.0647 & 0.2912 & 0.1122 & & & \\
\hline Bayes-Stein I & -0.0754 & 0.1538 & -0.0198 & -0.1321 & & \\
\hline Bayes-Stein II & -0.0537 & 0.1745 & 0.0002 & -0.1119 & 0.0201 & \\
\hline Bayes-Stein III & -0.0768 & 0.1525 & -0.0212 & -0.1334 & -0.0013 & -0.0214 \\
\hline \multicolumn{7}{|l|}{ Overall } \\
\hline Naive & -0.0578 & & & & & \\
\hline MVP & -0.0459 & 0.0136 & & & & \\
\hline Sharpe & -0.1714 & -0.1113 & -0.1209 & & & \\
\hline Bayes-Stein I & -0.1144 & -0.0547 & -0.0664 & 0.0527 & & \\
\hline Bayes-Stein II & -0.1853 & -0.1260 & -0.1341 & -0.0138 & -0.0676 & \\
\hline Bayes-Stein III & -0.0944 & -0.0350 & -0.0475 & 0.0727 & 0.0187 & 0.0873 \\
\hline
\end{tabular}

